\title{
Análise dos exames de perfil renal realizados no Hospital Universitário Ana Bezerra no período 2017 - 2018
}

\author{
Analysis of renal profile tests performed at the Ana Bezerra University Hospital at 2017 - 2018 \\ Análisis de los exámenes de perfil renal realizado en el Hospital Universitario Ana Bezerra en el periodo 2017 - 2018 \\ Alana Karoline Penha do NASCIMENTO ${ }^{1}$ \\ Brenda Lavínia Calixto dos SANTOS ${ }^{1}$ \\ Abrahão Alves de OLIVEIRA FILHO \\ Heloísa Mara Batista Fernandes de OLIVEIRA ${ }^{3}$ \\ ${ }^{1}$ Graduanda em Bacharelado em Farmácia, Centro de Educação e Saúde, Universidade Federal de Campina Grande - UFCG, 58175-000 Cuité-PB, Brasil \\ ${ }^{2}$ Farmacêutico - Bioquímico - Doutor em Farmacologia - Professor da Unidade Acadêmica de Ciências Biológicas - UACB \\ Centro de Saúde e Tecnologia Rural, Universidade Federal de Campina Grande - UFCG, 58700-970 Patos-PB, Brasil \\ ${ }^{3}$ Farmacêutica - Bioquímica - Doutora em Farmacologia, Hospital Universitário Ana Bezerra - HUAB/EBSERH, 59200-000 Santa Cruz-RN, Brasil
}

\section{Resumo}

Com o aumento da expectativa de vida dos brasileiros, houve também o crescimento da incidência de doenças crônicas degenerativas, como as alterações renais, que estão afetando cada vez mais a população como um todo, envolvendo o risco de desenvolver a insuficiência renal crônica e/ou aguda. Com isso é necessário à realização de exames laboratoriais rotineiros, a fim de se diagnosticar precocemente tais distúrbios, sendo necessária a solicitação dos marcadores laboratoriais. O propósito deste trabalho foi descrever o padrão de exames solicitados para a avaliação do perfil renal de pacientes atendidos no Hospital Universitário Ana Bezerra. A metodologia adotada trata-se de um estudo epidemiológico delineado como retrospectivo documental, em que foi analisado o quantitativo dos exames solicitados para a avaliação do perfil renal no banco de dados do Laboratório de Análises Clínicas do Hospital Universitário Ana Bezerra do período de junho de 2017 a junho de 2018. Diante da pesquisa realizada foi possível evidenciar que foram solicitados 31.159 exames para avaliar o perfil renal, sendo a creatinina o exame mais solicitado para os pacientes atendidos no Hospital Universitário Ana Bezerra.

Descritores: Rim; Testes de Função Renal; Creatinina.

\section{Abstract}

With the increase in the life expectancy of Brazilians, there has also been an increase in the incidence of chronic degenerative diseases, such as renal changes, which are increasingly affecting the population as a whole, involving the risk of developing chronic renal failure and / or acute With this, it is necessary to carry out routine laboratory tests in order to diagnose such disorders early, requiring laboratory markers. The purpose of this study was to describe the pattern of exams requested for the evaluation of the renal profile of patients attended at the Hospital Universitário Ana Bezerra. The methodology adopted is an epidemiological study designed as a retrospective documentary, in which the quantitative of the tests requested for the evaluation of the renal profile in the database of the Laboratory of Clinical Analysis of the Hospital Universitário Ana Bezerra from the period of June 2017 to June 2018. In view of the research, it was possible to show that 31,159 exams were requested to evaluate the renal profile, with creatinine being the most requested for patients attended at the Hospital Universitário Ana Bezerra.

Descriptors: Kidney; Kidney Function Tests; Creatinine.

\section{Resumen}

Con el aumento de la expectativa de vida de los brasileños, hubo también el crecimiento de la incidencia de enfermedades crónicas degenerativas, como las alteraciones renales, que están afectando cada vez más a la población como un todo, involucrando el riesgo de desarrollar la insuficiencia renal crónica y / o aguda. Con ello es necesario la realización de exámenes de laboratorio rutinarios, a fin de diagnosticar precozmente tales disturbios, siendo necesaria la solicitud de los marcadores de laboratorio. El propósito de este trabajo fue describir el patrón de exámenes solicitados para la evaluación del perfil renal de pacientes atendidos en el Hospital Universitario Ana Bezerra. La metodología adoptada se trata de un estudio epidemiológico delineado como retrospectivo documental en el que se analizó el cuantitativo de los exámenes solicitados para la evaluación del perfil renal en el banco de datos del Laboratorio de Análisis Clínicos del Hospital Universitario Ana Bezerra del período de junio de 2017 a junio de 2018. Ante la investigación realizada fue posible evidenciar que se solicitaron 31.159 exámenes para evaluar el perfil renal, siendo la creatinina el más solicitado para los pacientes atendidos en el Hospital Universitario Ana Bezerra.

Descritores: Riñón; Pruebas de Función Renal; Creatinina.

\section{INTRODUÇÃO}

Com o envelhecimento e o aumento da expectativa de vida da população brasileira, houve também um crescimento da incidência de doenças crônicas degenerativas. Segundo estudos feitos nos anos 1990 e 2000 observou-se uma acentuada transformação no perfil de mortalidade, onde se constatou que enquanto as mortes por doenças infecciosas e parasitárias não ultrapassavam 7,3\%, as mortes relacionadas às doenças crônicas não transmissíveis (DCNT) variavam de $30 \%$ a $34,3 \%{ }^{1}$.

Dentre essas doenças, a insuficiência renal crônica (IRC) necessita de uma maior atenção das autoridades de saúde, principalmente, devido à sua crescente prevalência nas faixas etárias mais elevadas. A prevalência aumenta com a idade, atingindo, na população idosa (60 anos ou mais de idade), valores 10 vezes maiores que no grupo etário de menores de 30 anos de idade. ${ }^{1}$ Além disso, trata-se de uma doença insidiosa, que causa sinais e sintomas apenas nos estágios finais de sua evolução. Logo, sua detecção demanda conhecimento técnico, acesso a exames e atenção redobrada dos profissionais de saúde $^{2}$.

Os pacientes que chegam aos serviços especializados em nefrologia apresentam, principalmente, uremia e anemia profunda. Tais fatos são indicativos de que a patologia foi descoberta tardiamente, apenas quando a condição de nefropata se torna muito evidente. Essas alterações urêmicas pioram o estado geral do doente e demandam uma assistência mais invasiva, elevando os custos do tratamento $^{3}$. Com a progressão da disfunção renal, os 
sintomas se tornam mais incisivos. Ocorre grande acúmulo de ureia, anemia progressiva, acidose metabólica e distúrbios nas concentrações de sódio, potássio, cálcio e fósforo ${ }^{4}$. O acúmulo de líquidos (água) se instala progressivamente no organismo, podendo causar edema grave, aumento da pressão arterial e insuficiência cardíaca congestiva em pacientes predispostos. Esses sintomas assumem um caráter mais grave se houver uma elevação significativa de sódio plasmático, resultado da dieta rica em sal de cozinha ${ }^{5}$.

Diante do exposto, ressalta-se a necessidade de determinar o perfil renal de pacientes como uma importante estratégia para se conhecer e diagnosticar precocemente alterações renais, que os resultados obtidos possam ser avaliados para futuras intervenções e ações mais específicas e adequadas. Assim, o objetivo do estudo foi descrever o quantitativo de exames solicitados para a avaliação do perfil renal de pacientes atendidos no Hospital Universitário Ana Bezerra (HUAB) no município de Santa Cruz/RN.

\section{MATERIAL E MÉTODO}

O presente trabalho trata-se de estudo epidemiológico delineado como retrospectivo documental, e desenvolvido no Laboratório de Análises Clínicas do HUAB utilizando-se os dados da produção de exames que avaliaram o perfil renal, recebidos no período de junho de 2017 a junho de 2018, com pacientes de ambos os sexos, todas as faixas etárias e locais de residência.

A coleta de dados foi realizada por meio do acesso aos dados armazenados no programa CompLab (fonte de dados gerada pelo laboratório) o qual gera um relatório mensal contendo a produção dos exames realizados. Os resultados foram organizados em planilhas no programa Microsoft ${ }^{\circledR}$ versão 2010.

\section{RESULTADOS E DISCUSSÃO}

Foram realizados 31.159 exames no laboratório de Análises Clínicas do HUAB para avaliar o perfil renal em pacientes, onde se pode observar o quantitativo desses exames no período de junho de 2017 a junho de 2018. O exame mais solicitado para triagem do perfil renal foi a creatinina, correspondendo a $40,15 \%$ dos exames solicitados, seguido da ureia $(37,35 \%)$, ácido úrico $(18,44 \%)$, cálcio $(3,85 \%)$ e os demais $(0.21 \%)$ conforme se observa na Tabela 1.

O rim é um órgão excretor, em forma de feijão, com aproximadamente $11 \mathrm{~cm}$ de comprimento, $5 \mathrm{~cm}$ de largura e $3 \mathrm{~cm}$ de espessura. É o principal órgão do sistema excretor e osmorregulador dos vertebrados. Filtra produtos do metabolismo de aminoácidos (especialmente ureia) do sangue, e os excretam, com água, na urina; a qual ganha a bexiga através dos ureteres ${ }^{6}$.
Tabela 1. Quantitativo dos exames solicitados para avaliação do perfil renal no Hospital Universitário Ana Bezerra no período de junho de 2017 a junho de 2018

\begin{tabular}{lcc}
\hline \multicolumn{1}{c}{ Exames } & $\begin{array}{c}\text { Quantitativo } \\
\text { bruto }\end{array}$ & $\begin{array}{c}\text { Quantitativo } \\
\text { em \% }\end{array}$ \\
\hline Creatinina & 12511 & $40.15 \%$ \\
\hline Uréia & 11638 & $37.35 \%$ \\
\hline Ácido úrico & 5433 & $17.44 \%$ \\
\hline Cálcio & 1201 & $3.85 \%$ \\
\hline $\begin{array}{l}\text { Relação microalbuminúria } \\
\text { urinária }\end{array}$ & 159 & $0.51 \%$ \\
\hline Poteinúria 24 horas & 129 & $0.41 \%$ \\
\hline Microalbuminúria em amostra isolada & 40 & $0.13 \%$ \\
\hline Cleanrence de creatinina & 11 & $0.04 \%$ \\
\hline Calciúria & 10 & $0.03 \%$ \\
\hline Ácido úrico na urina isolada & 7 & $0.02 \%$ \\
\hline Microalbuminúria em urina 24 horas & 7 & $0.02 \%$ \\
\hline Creatinina em urina isolada & 5 & $0.02 \%$ \\
\hline Proteinúria em amostra isolada & 5 & $0.02 \%$ \\
\hline Ácido úrico na urina 24 horas & 3 & $0.01 \%$ \\
\hline Total & 31159 & $100 \%$ \\
\hline Fonte: dados da Pesquisa & &
\end{tabular}

A creatinina é considerada o melhor marcador endógeno para função renal, já que permite avaliar o ritmo de filtração glomerular, apesar de suas concentrações plasmáticas e urinárias sofrerem interferência devido a sua pequena secreção essas interferências ainda são menores do que as sofridas por uréia e ácido úrico. Sua concentração sanguínea é proporcional à massa muscular. Por esse motivo, em situações de atrofia muscular e outras enfermidades relacionadas, ocorre diminuição do teor de creatinina plasmática. Ao mesmo tempo, em situações de exercício prolongado ou intenso, pode ser observado um aumento nos níveis plasmáticos de creatinina. A excreção de creatinina só se realiza por via renal, uma vez que ela não é reabsorvida nem reaproveitada pelo organismo. Por isso, os níveis de creatinina plasmáticos refletem a taxa de filtração glomerular, de forma que níveis altos de creatinina indicam uma deficiência na funcionalidade renal. Além disso, aumenta de forma significativa e rápida na insuficiência renal ${ }^{7,8}$.

A concentração de ureia pode estar aumentada em pacientes que alimentam-se com excesso de proteína ou dietas que possuem fontes de nitrogênio não protéico. $\mathrm{O}$ adequado fornecimento de glicídeos na dieta, quando há suplementação de compostos nitrogenados, evita o aumento excessivo dos níveis de ureia sanguínea. Além disso, o jejum prolongado pode causar aumento da proteólise endógena para utilizar aminoácidos como fonte energética, o que causa aumento na concentração de ureia. Esse marcador aumentado indica problemas renais como insuficiência renal ${ }^{8}$.

$\mathrm{O}$ ácido úrico é um produto de degradação das purinas, compostos nitrogenados encontrados em ácidos nucleicos (DNA e RNA). O ácido úrico no sangue é gerado pelo metabolismo das purinas nas células do corpo, e um pouco pela digestão de alguns alimentos, como fígado, anchovas, peixes, feijões e ervilhas, e algumas bebidas alcoólicas, como vinho e cerveja. A maior parte do ácido úrico é eliminada na urina, e um pouco nas fezes. Se houver aumento da 
produção ou diminuição da excreção, o ácido úrico pode se acumular no sangue (hiperuricemia). $O$ excesso de ácido úrico no sangue está relacionado com a gota, uma doença caracterizada por inflamação articular causada por cristalização do ácido úrico no líquido sinovial, e com distúrbios renais, por exemplo, cálculo renal ${ }^{9}$.

O cálcio $(\mathrm{Ca})$ total plasmático é dividido em cálcio livre ionizado (biologicamente ativo) e cálcio associado a moléculas orgânicas (proteínas) ou a ácidos orgânicos. Estas duas formas estão em equilíbrio e sua distribuição depende do $\mathrm{pH}$, da concentração de albumina e da relação ácido-base. Entre as funções do cálcio estão: constituição da matriz óssea, função de segundo mensageiro intracelular, participação da contração muscular e transmissão do impulso nervoso. $\mathrm{O}$ sistema endócrino envolvendo a vitamina $\mathrm{D}$, o paratormônio (PTH) e a calcitonina regulam os níveis sanguíneos de cálcio. $\mathrm{O}$ excesso de cálcio no sangue indica distúrbios renais como cálculo renal ${ }^{10}$.

A dosagem dos demais marcadores para avaliar o perfil renal foram pouco solicitadas em relação aos já mencionados. Isso se deve ao fato do processo de coleta ser inconveniente na prática clínica e sujeito a influência de diversos fatores. Muito embora alguns marcadores detectarem precocemente a insuficiência renal, tais como a dosagem de microalbuminúria ${ }^{11}$.

\section{CONCLUSÃO}

Portanto, pode-se concluir que os exames mais realizados, no banco de dados do Laboratório de Análises Clínicas do Hospital Universitário Ana Bezerra do período de junho de 2017 a junho de 2018, para avaliação do perfil renal foi à creatinina, que junto com os demais marcadores são importantes para o diagnóstico precoce de insuficiência renal crônica e aguda, bem como o monitoramento de suas comorbidades.

Com isso, sugere-se que mais estudos sejam realizados no intuito de encontrar marcadores cada vez mais específicos e seletivos que permitam diagnosticar estas alterações precocemente e, dessa forma, melhorar a qualidade de vida dos pacientes.

\section{REFERÊNCIAS}

1. Brasil. Ministério da Saúde. Indicadores e Dados Básicos: Brasil - 2009 IDB-2009 Brasília: Ministério da Saúde. Disponível em: http://tabnet.datasus.gov/. Acesso em 11 Agosto 2018.

2. Begman R. Avaliação de pacientes com doença renal crônica em tratamento especializado por equipe multidisciplinar. J Bras Nefrol. 2006;28(3 Supl 2):33-5.

3. Godinho TM, Lyra TG, Braga OS, Queiroz RA, Alves JA, Kraychete AC et al. Perfil do paciente que inicia hemodiálise de manutenção em Hospital Público de Salvador, Bahia. J Bras Nefrol. 2006;28(2):96-103.

4. Zawada ET. Inicio da diálise. In: Daugiardas JT, Blake PG, Ing T. Manual de Diálise. 3. ed. Rio de Janeiro: Guanabara Koogan; 2003. p.4-11.

5. Kohagura K, Tomiyama N, Kinjo K, Takishita S, Iseki K. Prevalence of anemia according to stage of chronic kidney disease in a large screening cohort of Japanese. Clin Exp Nephrol. 2009; 13(6):614-20.

6. Guyton AC, Hall JE, Guyton AC. Tratado de fisiologia médica. Elsevier Brasil; 2006.

7. Azevedo AC, Gómez JFB, Lugon JR, Graciano ML. Detecção de disfunção renal através da dosagem de creatinina em amostra de gota de sangue seca no papel filtro. J Bras Nefrol. 2016; 38(1):15-21.

8. Silva Junior, Matos SMA. Padrões alimentares e doença renal crônica. In: Cruz J, Cruz HMM, Kirsztajn GM, Oliveira RB, Barros RT (eds). Atualidades em Nefrologia. 14.ed. São Paulo: Sarvier; 2016.

9. Tizatto LAP, Machado RAF. Exames diagnósticos e tratamento de urolitíase: uma revisão da literatura. Thêma et Scientia. 2016;6(1):212-29.

10.Telles C, Boita ERF. Importância da terapia nutricional com ênfase no cálcio, fósforo $\mathrm{e}$ potássio no tratamento da doença renal crônica. Perspectiva Erechim. 2015;39(145):143-54.

11.Bottini PV, Afaz SH, Silveira S, Garlipp CR. Utilização da relação albumina/creatinina no diagnóstico de microalbuminúria. J Bras Patol Med Lab. 2005;41(2):99-103.

\section{CONFLITO DE INTERESSES}

Os autores declaram não haver conflitos de interesse.

\section{AUTOR PARA CORRESPONDENCIA}

\section{Alana Karoline Penha do Nascimento}

alana_penha2011@hotmail.com

Submetido em 31/08/2018

Aceito em 04/10/2018 